\title{
ENTRE INCLUSÃO SOCIAL E LIVRE-INICIATIVA: O “CASO RESERVA RAPOSA SERRA DO SOL" E O PAPEL DO PODER JUDICIÁRIO NA CONSTRUÇÃO DE POLÍTICAS PÚBLICAS
}

\section{BETWEEN SOCIAL INCLUSION AND FREE ENTERPRISE: THE “RAPOSA SERRA DO SOL RESERVE” CASE AND THE JUDICIARY POWER ROLE ON THE PUBLIC POLICIES CONSTRUCTION}

\author{
Antonio Celso Baeta Minhoto* \\ Universidade Cruzeiro do Sul, Brasil \\ antonio@baetaminhoto.com.br \\ WaLlace Ricardo Magri** \\ Escola Paulista de Direito, Brasil \\ wallace@magriadvogados.com.br
}

\section{RESUMO:}

$\mathrm{O}$ ativismo judicial, especialmente aquele produzido pelas mais altas cortes em seus países - e no caso do Brasil de forma marcante pelo Supremo Tribunal Federal - é um dos temas mais ricos para um debate contemporâneo dentro do direito, de modo especial quanto à concretização de políticas públicas, bem como a potencial inclusão social que tais políticas acarretem ou possam acarretar. Há

\footnotetext{
* Doutor em Direito Público pela Instituição Toledo de Ensino de Bauru, SP; Mestre em Direito Político e Econômico pela Universidade Presbiteriana Mackenzie, São Paulo, SP; Coordenador dos Cursos de PósGraduação em Direito na Universidade Cruzeiro do Sul, sistema EAD; Professor Titular de Direito Público na Universidade Municipal de São Caetano do Sul, SP; Advogado; autor de obras jurídicas. antonio@baetaminhoto.com.br.

** Doutor e Mestre em Semiótica e Linguística Geral pela FFCLH/USP, possui graduação em Direito pelo Centro Universitário das Faculdades Metropolitanas Unidas; pós-graduação em Direito Penal pelo Centro Universitário das Faculdades Metropolitanas Unidas. Leciona Metodologia da Pesquisa Científica em Cursos de Pós-Graduação (atualmente na Escola Paulista de Direito - EPD e Escola Superior de Advocacia - ESA). Advogado atuante em São Paulo. Autor de obras jurídicas. wallace@magriadvogados.com.br.
} 
que se ponderar, contudo, que a inclusão social não pode ser um valor absoluto, devendo se harmonizar com outros valores igualmente relevantes, sendo que no caso destacamos a livre iniciativa e a atividade empresarial. Ao final, como uma referência analítica, trazemos o caso da Reserva Raposa Serra do Sol, demarcada em julgamento do STF.

\section{Palavras chave:}

Ativismo judicial; minorias; atividade econômica; livre-iniciativa.

\section{ABSTRACT:}

The judicial activism, specially the one that comes from the highest courts all around the world —and, in Brazil's example, in a remarkable way by the Supremo Tribunal Federal-, is certainly one of the richest issues for a contemporary debate inside law studies, specially towards the public policies concretization, as well the social inclusion that its policies could bring. We must consider, in the other hand, that social inclusion couldn't be a absolute value, ought to be harmonized with other relevant values, and, in this case, we contrasted the free enter enterprise and the business activity. At the end, as a analytical reference, we brought the Raposa Serra do Sol leading case, delimited on a STF judgment.

\section{Keywords:}

Judicial activism; minorities; economical activity; free enterprise.

\section{INTRODUÇÃO}

O ativismo judicial vem sendo objeto de discussões não somente no campo jurídico, seu campo de manifestação evidente, mas do mesmo modo em outras áreas, especialmente na política, na sociologia e também na economia, que, neste estudo, será objeto de uma atenção mais detida.

Parece evidente, conquanto se revele útil frisar, que a abordagem econômica aqui pretendida é aquela voltada especificamente ao desenvolvimento econômico, tal como estampado e tratado no artigo 170 e seguintes da Constituição Federal, e não algo mais afeto a uma teoria econômica.

Esse olhar para o desenvolvimento econômico em intercruzamento com o ativismo judicial recebe, ainda mais, a questão das minorias como um tema-base do estudo presente, afinal, o julgamento ocorrido no STF para delimitar a Reserva Raposa Serra do Sol — adotada aqui como base analítica concreta- envolveu de modo direto uma minoria, no caso os indígenas.

Referido julgamento, conquanto aplaudido por muitos como uma suposta demonstração do que se poderia nominar de "bom ativismo", teve forte impacto sobre a economia local, especialmente com relação a atividade agrícola, cuja localização completa se dava justamente na área demarcada pelo Supremo Tribunal Federal, passando a ser, de tal julgamento em diante, terra indígena, e local de onde os produtores rurais tiveram que se retirar. 
Saber até que ponto o julgamento em foco atingiu os objetivos esperados de uma decisão tão ampla e com consequências tão profundas para a realidade local em que se encontra a reserva, descortinar as características do ativismo judicial e como sua manifestação está se dando em solo brasileiro e, por fim, projetar que tipo de consequências podem ser intuídas do inter-relacionamento de todos esses elementos, é o objetivo central deste estudo.

\section{ATIVISMO JUDICIAL E SEPARAÇÃO DOS PODERES ESTATAIS}

Pela expressão ativismo judicial se buscou e ainda se busca caracterizar aquela conduta de protagonismo adotada pelo Poder Judiciário quanto à consecução, implementação e concreção de políticas públicas ou mesmo princípios e/ ou valores estampados, via de regra, na constituição.

Essa ideia, no entanto, deve ser melhor entendida e, inclusive, ver-se inserida na questão da teoria da separação dos poderes estatais, a fim de se evitar juízos superficiais ou apressados quanto aos seus caracteres mais destacados.

Como é de conhecimento comum, a separação dos poderes não é um instituto exatamente de criação de Monstesquieu, tal como exposto em sua conhecida obra o "Espírito das Leis", mas foi ali que a simples noção de repartição do poder estatal ganhou um tratamento mais detido, mais efetivo e até mais dedicado.

O móvel fundamental da separação ou repartição dos poderes estatais é a limitação do poder. Sob a fórmula dos "freios e contra-pesos" (checks and balances), ou seja, da mútua fiscalização exercida por um poder em relação ao outro, repousa o que parece ser o real motivo de tal concepção: gerar ou obter uma real limitação do poder estatal.

A obra acima destacada é de 1748 e se voltava, como não poderia ser de outro modo, às condições sócio-políticas dadas àquela altura, fundamentalmente ligadas a uma estrutura de um poder absolutista, no que se refere ao campo político, e ainda buscando um rumo em busca da modernidade, relativamente ao campo social.

Montesquieu sabia - ecoando um sentimento que ia se sedimentando naquele momento - que o poder praticamente ilimitado do rei era conclusivamente um incômodo para uma sociedade que aspirava desenvolvimento e principalmente liberdade e, nesta linha conceitual, projetou a repartição desse poder político como forma de se conceber uma nova estrutura política, bem como social. Separar os poderes estatais, assim, surgiu fundamentalmente como forma de se evitar o arbítrio e limitar esses poderes.

Com o advento da Revolução Industrial (1756-1850, circa), mas especialmente com as mudanças sociais, econômicas e políticas consolidadas notadamente do início até meados do século XX, o Estado foi chamado a cumprir funções muito mais diversificadas e complexas em relação àquelas observadas no século XVIII, quando surge a teorização da separação dos poderes.

E neste ponto podemos agregar à limitação do poder também o conceito de um ganho administrativo, de um ganho em termos de eficiência para as ações estatais com a adoção da separação dos poderes. 
De fato, parece claro que a segmentação de atividades, em qualquer estrutura administrativa, tem por conseqüência a especialização de cada setor ou área em relação às atividades típicas ali desenvolvidas, o que redunda num aprofundamento da expertise típica de tais funções, seja em relação ao desenvolvimento de métodos e procedimentos próprios, seja no incremento técnico em si, no avanço tecnológico e de conhecimentos relativamente a tais atividades.

Esse ganho administrativo ganhou especial relevo com a mudança da configuração estatal observada especialmente na primeira metade do século XX. De um Estado absenteísta e imerso num liberalismo de feição ainda bastante ortodoxa, com, ainda mais, poucas ou limitadas funções a desempenhar, o começo do século passado vê surgir um Estado de feição mais social, gradativamente voltado à implementação e proteção de direitos coletivos.

Além desses direitos, o Estado que surge dessa inflexão de forças e de eventos históricos $-1^{a}$ Guerra Mundial, Revolução Russa, Constituição Mexicana, Constituição de Weimar - também assume um papel muito mais protagônico na atividade econômica, algo que encontrará uma espécie de síntese na política do New Deal de Roosevelt, nos EUA.

Esse "novo" Estado, tal como acima exposto, se vê assim às voltas com muitas outras atividades inexistentes ao tempo da teorização primitiva da separação dos poderes. A limitação do poder segue sendo importante neste contexto, mas o ganho de eficiência em termos administrativos, a obtenção de uma burocracia estatal mais eficiente, é um ponto a ser levado em conta, especialmente quando buscamos uma análise mais contemporânea da repartição do poder estatal.

Outro aspecto de relevo, ainda neste contexto de contemporaneidade, é que os elementos acima destacados, limitação do poder e ganho em eficiência administrativa, são como que inspirados por uma ideia que passa a ser um verdadeiro princípio informativo: equilíbrio entre os poderes estatais. Equilíbrio e harmonia.

Sai de cena a separação estanque, a noção de compartimentos rigorosamente independentes que, por vezes, lutam para demarcar com a máxima rigidez seus próprios limites, e os limites dos outros poderes, para se adotar uma visão de convívio entre independência e equilíbrio como elementos inerentes a esta segmentação de poderes estatais.

Esta visão, a bem da verdade, nem é exatamente tão contemporânea assim, eis que Carl Schmitt, por exemplo, já a indicava como sendo um elemento vital, anotando que "a constituição inglesa representada por Montesquieu garante a liberdade dos cidadãos não através da separação dos poderes, mas através do equilibrio dos poderes". ${ }^{1}$ E na mesma linha segue Madame de Staël-Holstein: ${ }^{2}$

$\mathrm{O}$ equilíbrio dos poderes não significa o jogo dos contrapesos, que nada mais seria do que um equilíbrio de forças que originaria um conflito ininterrupto entre os poderes para obter a supremacia. Equilibrar os poderes significa a série de combinações que os leva a encontrar um acordo.

1 SCHMITT, Carl. O conceito do político. Petropolis: Vozes, 1992, p. 85.

2 Lettres sur les ouvrages et le caractère de Jean-Jacques Rousseau (1788), apud SCMITT, op. cit., p. 86. 
O equilíbrio harmônico defendido pelos doutrinadores destacados, bem de se ver, se encontra previsto em nossa Constituição Federal que não apenas contempla a repartição de poderes do Estado, mas expressamente defende que esta seja harmoniosa entre os elementos componentes dessa separação (Executivo, Legislativo e Judiciário), sem prejuízo da independência de cada um deles no desempenho de suas funções (art. $2^{\circ}, \mathrm{CF}$ ).

Não é, portanto, exatamente na avaliação estrita e rigorosa do desempenho das funções tidas como típicas de cada poder estatal que se encontra o âmago ou mesmo a necessidade de tal separação. Nem mesmo na observação detida dos limites de cada poder na articulação das ações que lhe são próprias ou peculiares, mas, ao menos com muito mais força, é no equilíbrio e no convívio harmônico entre tais poderes que está o real foco de interesse de suas repartições.

$\mathrm{O}$ contraponto acima se afigura relevante, pois, se aos juízes e magistrados de um modo geral recomenda-se cautela na condução da prestação jurisdicional, justamente para se evitar "invasões" sobre procedimentos próprios de outros poderes estatais, não menos certo é se observar que estes chamados — freqüentemente de modo desproporcional e bastante adjetivado - "excessos" ou "abusos" do ativismo judicial, nada mais são que atos perfeitamente normais ou pelo menos aceitáveis no contexto contemporâneo de um Estado de Direito, mais ainda quando à sua natureza jurídica (de direito) se agrega o elemento da democracia (democrático de direito).

Contemporaneamente, às muitas atividades que o Estado passa a desempenhar ou aos muitos atos e procedimentos que lhe são titularizados, ainda devemos agregar o exercício de um papel ativo na concreção de direitos fundamentais, de elementos integrantes da democracia, ou a própria democracia como um todo, mas, de modo vital, na consecução de políticas públicas, especialmente aquelas disposta ou contempladas em normas positivadas.

É precisamente neste último aspecto que se insere, no final, o âmago do que se poder nominar como sendo um verdadeiro ativismo judicial. Como já se disse acima, não é qualquer ato pretensamente heterônomo praticado pelo Poder Judiciário que poderá ser classificado, e no mais das vezes criticado, como sendo a prática do ativismo judicial, mas fundamentalmente aquele que, descolando-se do ato jurisdicional mais ortodoxo ou clássico, visa o atingimento de um alvo exclusivo ou precipuamente político por meio de um julgamento.

Neste contexto, a prestação jurisdicional -especialmente dos tribunais superiores e ainda mais especialmente do Supremo Tribunal Federal-cumpre o papel de dar uma solução definitiva para a lide ali contida, mas, também, e até principalmente em alguns casos, se posiciona como um ator ativo, relevante e eficaz na tarefa de tornar realidade certos valores e princípios públicos contemplados pelo Estado de um modo geral em suas normas.

Se isso é feito com excesso ou de modo desaconselhável, não apenas pelo excesso, mas por sua própria manifestação, é algo a ser analisado numa abordagem caso a caso, justamente o foco desse nosso estudo, com o estudo, mesmo limitado, de um julgamento referencial produzido pelo STF. 
Antes, porém, se analisará o ativismo judicial no Brasil de um modo mais amplo, objeto de estudo de nosso próximo tópico.

\section{ATIVISMO JUDICIAL NO BRASIL E SEUS REFLEXOS}

O transporte de funções entre os poderes não é algo novo e nem deveria causar surpresa, como já se referenciou acima. A questão que parece relevante é observar a intensidade desse fenômeno, especialmente no Brasil.

Assim, e ilustrativamente, a figura da medida provisória, de tão larga utilização em solo brasileiro, teve clara inspiração no decreto-legge italiano onde, sob a égide da constituição de 1947, ainda vigente, segue sendo instituto posto à disposição do presidente da República. Contudo, como ali vigora, desde aquele momento, o regime parlamentarista, observa-se que a amplidão de tal instituto é ali, até de modo natural, muito mais contida.

No Brasil essa amplidão de atuação do executivo tampouco é algo tradicional e linear. Com efeito, somente as constituições de 1937, 1967 e a Emenda Constitucional $\mathrm{n}^{\mathrm{o}} 1$, de 1969 , considerada por alguns como uma nova constituição, traziam o instrumento da medida provisória, o que foi retomado pela Constituição Federal de 1988.

A exposição acima não é articulada no sentido de se justificar eventuais excessos do STF no exercício de suas funções, uma espécie de paralelo analógico com a atuação do executivo, mas tão-somente mostrar a realidade político-institucional em que o exercício das atividades típicas dos poderes estatais se desenvolve no Brasil. Há, inegavelmente, uma dinâmica toda própria ou peculiar no sentido ora exposto.

A Constituição Federal, como é de conhecimento comum, foi proposta, debatida e finalmente promulgada num ambiente pós-ditadura, num "clima" de recente democratização do país, processo que, muito embora infindável por natureza, no caso brasileiro ainda mostra claras lacunas a reclamar integração.

Em locução que acabou por se consagrar na doutrina, o professor Lenio Streck se refere ao Brasil como exemplo de nação "de modernidade tardia" , ou seja, integrante de um grupo de estados que ainda não completaram a tarefa já concluída por países desenvolvidos de garantir a concretização de direitos fundamentais - destacadamente os individuais de primeira e segunda geração- e implementação definitiva da democracia.

O pré-citado professor defende que, para lidar com essa realidade, devemos ter aqui uma postura ativista de nossos tribunais, com o escopo central de concretizar direitos e políticas públicas, especialmente aquelas dispostas na Constituição Federal, o que atrai naturalmente o STF para um papel de destaque neste sentido.

Como parece ser bastante evidente, a linha adotada acima não é livre de resistências, dentro e fora do Brasil. Talvez o mais destacado crítico dessa postura ativista (e também "substancialista"), seja o filósofo Jürgen Habermas, que, nesta discussão, ficou alinhado ao que se usou nominar de "procedimentalistas".

3 STRECK, Lenio. Novos Estudos Jurídicos. Volume 8. № 2. p.257-301, maio/ago. 2003. 
Para os "procedimentalistas", o verdadeiro espaço de construção da democracia é o parlamento, e isso não somente porque sua composição partiu de uma escolha popular, mas também porque se trata de um órgão de proporções muito maiores que uma corte constitucional, composta, normalmente, de alguns poucos juízes ou ministros, e também porque o parlamento, justamente por ser órgão de composição popular, está muito mais permeável às interferências críticas da população, o que não ocorre com uma corte constitucional ou mesmo com a atividade jurisdicional de um modo geral.

Habermas critica duramente o papel desempenhado especialmente pelas cortes constitucionais na dinâmica político-social, chegando a afirmar que "ao deixarse conduzir pela ideia da realização de valores materiais, dados preliminarmente no direito constitucional, o tribunal constitucional transforma-se numa instância autoritária" e mais adiante ainda completa sua crítica vendo na atuação do Judiciário relativamente às grandes questões da cidadania uma "colonização do mundo da vida". ${ }^{4}$

De modo bastante direto, Habermas defende que o tribunal constitucional "deve ficar limitado à tarefa de compreensão procedimental da Constituição (...) limitando-se a proteger um processo de criação democrática do direito". 5

Em contrapartida, os "procedimentalistas" são criticados por se isolarem demasiadamente numa realidade de nações já desenvolvidas, incluindo aí o campo político e social. Habermas, assim, estaria fazendo uma abordagem excessivamente centrada na realidade européia, notadamente alemã, ignorando outras realidades em que o papel do Judiciário pode ser relevante na construção de uma sociedade mais desenvolvida e avançada em termos humanísticos.

Com relação ao Brasil, já se registrou algumas manifestações importantes de ministros do Supremo Tribunal Federal sobre o tema, seja em votos de ações ou recursos, seja em manifestações extra-autos. Vejamos:

Justificar-se-á, como procedimento já enfatizado —e até mesmo por razões fundadas em um imperativo ético-jurídico - a possibilidade de intervenção do Poder Judiciário, em ordem a viabilizar, a todos, o acesso aos bens cuja fruição lhes haja sido injustamente recusada pelo Estado (ADPF 45/DF, Relator Min. Celso de Mello)

Enfatizo tão-somente que, tendo em vista as imperiosas balizas constitucionais que demandam a concretização do direito de greve a todos os trabalhadores, este Tribunal não pode se abster de reconhecer que, assim como se estabelece o controle judicial sobre a atividade do legislador, é possível atuar também nos casos de inatividade ou omissão do legislativo (MI 712-8, Rel. Min. Eros Grau, voto de Gilmar Mendes)

Existem três situações em que cabe a intervenção do Judiciário nas políticas públicas: quando a omissão ou a política já implementada não oferecer condições mínimas de existência humana; se o pedido de intervenção for razoável; e, do ponto de vista administrativo, a omissão ou a política seja desarroazoada. Em todos os

4 HABERMAS, J. Direito e Democracia - entre faticidade e validade. vol. I, Rio de Janeiro: Tempo Brasileiro, 1997, p. 245 e segs.

5 Ibidem, p. 247. 
casos, é preciso que haja verba para a implementação das medidas (Limites ditados pelo voto do Ministro Celso de Mello na ADPF 45)

Embora inquestionável que resida, primariamente, nos Poderes Legislativo e Executivo, a prerrogativa de formular e executar políticas públicas, revela-se possível, no entanto, ao Poder Judiciário, ainda que em bases excepcionais, determinar, especialmente nas hipóteses de políticas públicas definidas pelo própria Constituição, sejam estas implementadas, sempre que órgãos estatais competentes, por descumprirem os encargos político-jurídicos que sobre eles incidem em caráter mandatórios, vierem a comprometer, com a sua omissão, a eficácia e a integridade de direitos sociais e culturais empregados na estrutura constitucional (AI 677.2748/SP, Rel. Min. Celso de Mello)

Práticas de ativismo judicial, embora moderadamente desempenhadas por esta Corte em momentos excepcionais, tornam-se uma necessidade institucional, quando os órgãos do Poder Público se omitem ou retardam, excessivamente, o cumprimento de obrigações a que estão sujeitos por expressa determinação do próprio estatuto constitucional, ainda mais se se tiver presente que o Poder Judiciário, tratando-se de comportamentos estatais ofensivos à Constituição, não pode se reduzir a uma posição de pura passividade (Min. Celso de Mello, discurso de posse do Presidente do STF, Ministro Gilmar Mendes, abril de 2008)

Mas, ainda que o ativismo possa ser visto como uma espécie de necessidade para países como o Brasil, o fato é que a fixação de limites para tal atividade - e o próprio questionamento sobre sua relevância como elemento edificador da democracia brasileira - segue sendo tema candente, imerso em polêmica ainda bastante viva e cujo equacionamento não parece ser nem simples e nem de alcance fácil num horizonte mediano de tempo.

Bem por isso, iremos destacar, logo adiante, caso submetido ao crivo do Supremo Tribunal Federal em que o ativismo judicial se mostrou bastante presente. Trata-se do caso que ficou conhecido como "Reserva Raposa Serra do Sol" em que a corte maior do país determinou a demarcação continua de reserva indígena já existente e o fez colocando de lado certos direitos para prestigiar outros.

\section{O CASO DA RESERVA INDÍGENA "RAPOSA SERRA DO SOL”}

Raposa Serra do Sol (Raposa) é uma área de terra indígena situada no nordeste do estado brasileiro de Roraima, nos municípios de Normandia, Pacaraima e Uiramutã, entre os rios Tacutu, Maú, Surumu, Miang e a fronteira com a Venezuela, foi criada destinada à posse permanente dos grupos indígenas ingaricós, macuxis, patamonas, taurepangues e uapixanas. ${ }^{6}$

A Raposa foi demarcada pelo Ministério da Justiça, através da Portaria $\mathrm{N}^{\mathrm{o}}$ 820/98, posteriormente modificada pela Portaria 534/2005. A demarcação foi homologada por decreto de 15 de abril de 2005, da Presidência da República. ${ }^{7}$

6 Disponível em http://pt.wikipedia.org/wiki/Raposa_Serra_do_Sol, acesso em 19 de novembro de 2017.

7 Disponível em http://www.justica.gov.br/Acesso/auditorias/arquivos_auditoria/pf/parana/relatorio_gestao_2008_dpf_pr.pdf/view, acesso em 19 de novembro de 2017. 
A reserva destacada é uma das maiores porções de terra indígena do país, com 1.743.089 hectares e 1000 quilômetros de perímetro. Quase 27\% do território amazônico hoje é ocupado por terras indígenas, sendo que 46,37\% de Roraima correspondem a estas áreas. ${ }^{8}$

Formada por imensas planícies, semelhantes às das regiões de cerrado, e por cadeias de montanhas, na fronteira entre Brasil, Venezuela e Guiana, a Raposa acabou atraindo produtores rurais que passaram a se dedicar ao cultivo de arroz, eis que as terras eram de boa qualidade.

Esses produtores de arroz teriam chegado à região no início da década de 1970, quando compraram as terras de antigos fazendeiros. Até 2008/2009, eram produzidas ali 160.000 toneladas de grãos por ano, em uma área de aproximadamente 100 mil hectares, na borda sul da reserva Raposa Serra do Sol, às margens do Rio Surumu. ${ }^{9}$

O impacto da produção agrícola na região era de tal magnitude que o governo estadual de Roraima incentivava a vinda de novos produtores e também lhes fornecia calcário - para utilização na lavoura - a preços subsidiados ou mesmo gratuitamente em certos casos.

Como resultado dos conflitos constantes entre produtores rurais e índios, foi determinada a desocupação de toda a área da reserva em 2007. Em 2008, contudo, o Estado de Roraima interpôs uma representação no STF (Pet 3388) reivindicando a suspensão da ordem de desocupação. A representação foi acatada por unanimidade no Supremo e a chamada Operação Upatakon III foi suspensa até o julgamento de todos os processos relativos à homologação das terras indígenas.

Em 20 de março de 2009, julgamento do STF, no bojo da já citada Pet 3388, confirmou a homologação contínua da Reserva Indígena Raposa Serra do Sol, determinando a retirada dos não indígenas (produtores rurais) da região. O Relator designado, Ministro Ayres Brito, liderou o entendimento acima destacado e suas considerações acabaram integrando a ementa do julgamento, valendo destacar alguns trechos relevantes:

Os direitos dos índios sobre as terras que tradicionalmente ocupam foram constitucionalmente "reconhecidos", e não simplesmente outorgados, com o que o ato de demarcação se orna de natureza declaratória, e não propriamente constitutiva. Ato declaratório de uma situação jurídica ativa pré-existente. Essa a razão de a Carta Magna havê-los chamado de "originários", a traduzir um direito mais antigo do que qualquer outro, de maneira a preponderar sobre pretensos direitos adquiridos, mesmo os materializados em escrituras públicas ou títulos de legitimação de posse em favor de não-índios. Atos, estes, que a própria Constituição declarou como "nulos e extintos" ( $\$ 6^{\circ}$ do art. 231 da CF).

O modelo de demarcação das terras indígenas é orientado pela ideia de continuidade. Demarcação por fronteiras vivas ou abertas em seu interior, para que se forme um perfil coletivo e se afirme a auto-suficiência econômica de toda uma

8 Disponível em http://www.conteudojuridico.com.br/pdf/cj031397.pdf, acesso em 19 de novembro de 2017.

9 ALBANO, Gleidson Pinheiro. Globalização da Agricultura: uma análise comparativa entre duas cidades com fruticultura irrigada para exportação no RN, Ipanguaçu e Baraúna. Disponível em https://www.ufpe.br/posgeografia/images/documentos/d_2012_gleidson_pinheiro_albano.pdf, acesso em 19 de novembro de 2017. 
comunidade usufrutuária. Modelo bem mais serviente da ideia cultural e econômica de abertura de horizontes do que de fechamento em "bolsões", "ilhas", "blocos" ou "clusters", a evitar que se dizime o espírito pela eliminação progressiva dos elementos de uma dada cultura (etnocídio).

Cada etnia autóctone tem para si, com exclusividade, uma porção de terra compatível com sua peculiar forma de organização social. Daí o modelo contínuo de demarcação, que é monoétnico, excluindo-se os intervalados espaços fundiários entre uma etnia e outra. Modelo intraétnico que subsiste mesmo nos casos de etnias lindeiras, salvo se as prolongadas relações amistosas entre etnias aborígines venham a gerar, como no caso da Raposa Serra do Sol, uma condivisão empírica de espaços que impossibilite uma precisa fixação de fronteiras interétnicas. Sendo assim, se essa mais entranhada aproximação física ocorrer no plano dos fatos, como efetivamente se deu na Terra Indígena Raposa Serra do Sol, não há como falar de demarcação intraétnica, menos ainda de espaços intervalados para legítima ocupação por não-índios, caracterização de terras estaduais devolutas, ou implantação de Municípios.

Especificamente com relação aos aspectos de desenvolvimento econômico e impacto da demarcação na realidade produtiva local, o julgamento em foco posicionou-se no sentido de haver aí um "falso dilema" entre desenvolvimento e demarcação de reservas indígenas, ponderando que ao poder público:

De todas as dimensões federativas o que incumbe não é subestimar, e muito menos hostilizar comunidades indígenas brasileiras, mas tirar proveito delas para diversificar o potencial econômico-cultural dos seus territórios (dos entes federativos). $\mathrm{O}$ desenvolvimento que se fizer sem ou contra os índios, ali onde eles se encontrarem instalados por modo tradicional, à data da Constituição de 1988, desrespeita o objetivo fundamental do inciso II do art. $3^{\circ}$ da Constituição Federal, assecuratório de um tipo de "desenvolvimento nacional" tão ecologicamente equilibrado quanto humanizado e culturalmente diversificado, de modo a incorporar a realidade indígena.

Por outro lado, registre-se, especificamente quanto ao âmago do julgamento em comento, não existir consenso nem mesmo entre os índios quanto à desocupação dos não-índios, no caso produtores rurais. Aqueles organizados em torno do Conselho Indígena de Roraima apoiam, enquanto outros ligados à Sociedade de Defesa dos Indígenas Unidos do Norte de Roraima (Sodiur) são contrários à saída dos não índios da região. ${ }^{10}$

Estes últimos argumentam que vários índios trabalhavam nas lavouras de arroz e que a relação com os produtores rurais era ao menos estável. Mas, tudo leva a crer que esse grupo não foi ouvido ou não foram consideradas as suas colocações como razões de decidir por parte do Supremo Tribunal Federal.

O que se observa, num olhar critico, é que o julgamento em foco parece não ter levado em conta alguns aspectos:

A. Não parece ter sido considerado no bojo do julgamento o fato de que muitos produtores rurais ali estavam instalados há muito tempo e o faziam de

10 Romero Jucá, senador por Roraima, se pronunciou sobre este aspecto: http://www.senado.gov.br/atividade/ pronunciamento/detTexto.asp?t=369812, acessado em 10 de setembro de 2017. 
boa-fé e, ainda mais, apoiados em títulos regulares. Parece ser de pouca juridicidade, ainda mais, contrastar tais títulos com o direito dos índios que seria meta-jurídico ou transcendental, eis que, se assim fosse, estariam os índios, então, acima das próprias disposições de um Estado Democrático de Direito, configurando uma espécie de demiurgos reunidos em grupo;

B. A ocupação das terras pelos não-índios era com claro viés produtivo, algo que impactava positivamente não somente na atividade econômica do Estado de Roraima, mas na vida de muitos índios, ligados de algum modo a atividade rural desenvolvida naquela região. Tudo leva a crer que estes indivíduos, também índios, simplesmente não foram ouvidos;

C. Como bem observou o Ministro Marco Aurélio Mello em seu voto divergente, nenhum prejuízo experimentariam os índios com a demarcação descontínua de suas terras, eis que já há entre eles uma divisão natural em subgrupos étnicos, compostos por povos com dialeto, hábitos, costumes e cultura diferenciadas entre si. A demarcação contínua não parece ter representado, pois, qualquer ganho neste sentido. E falar em marcação contínua para se evitar um "etnocídio" revela abordagem excessivamente subjetiva e até mesmo panfletária, algo inadequado no contexto de um julgamento como esse;

D. O julgamento não revela, como deveria, ter ocorrido aqui uma real ponderação de valores, buscando-se uma solução parcimoniosa que procurasse a harmonização dos interesses em jogo e não a simples adjudicação de um direito em prol de uma parte sem se considerar, com a profundidade devida, os interesses dispostos no entorno da questão. Desse modo, transparece que o direito à demarcação foi posto acima de quaisquer outras considerações, transmutando-se numa espécie de "superdireito" a ser tutelado a todo e qualquer custo, o que não é recomendável para a solução de um conflito complexo como esse.

E. A Reserva possui mais de 1,7 milhões de hectares, sendo que a área ocupada pelos produtores de arroz alcançava apenas 160.000 hectares, ou seja, menos de $10 \%$ da área da Reserva. A simples exposição desse dado parece ser suficiente para autorizar a conclusão que, de fato, faltou equilíbrio e ponderação no julgamento em foco.

\section{CONSIDERAÇÕES FINAIS}

O presente artigo já traz em seu bojo as considerações e observações críticas cabíveis neste estudo. Restam algumas poucas observações finais que funcionarão como fecho dessa reflexão.

Pode-se dizer que o Ativismo Judicial foi bem exemplificado neste caso, quando, na busca de efetivar sua função de guardião da Constituição Federal, acabou o STF não "apenas" exercendo funções legislativas, mas verdadeiramente agindo como se agente político integrante do executivo fosse, como se formulador e implementador de políticas públicas fosse, o que está longe de ser atividade típica do Poder Judiciário e está distante até mesmo de ser atividade atípica, indireta ou imprópria. 
Nota-se que o chamado ativismo judicial, ao menos no Brasil, vem atrelado fundamentalmente à ideia de uma participação ampla e intensa do Judiciário na consolidação dos valores constitucionais e isso quase sempre para garantir a fruição de direitos pelos grupos minoritários.

Há exemplos candentes relacionados a isso, como o julgamento da união homossexual e também o julgamento da política de cotas pelo viés étnico, o que também envolve os índios como beneficiários. Nestes dois casos, notadamente no segundo, houve intensa consulta prévia ao julgamento, com sessões públicas em que especialistas puderam expor suas posições subsidiando os julgamentos futuros.

No caso da Reserva Raposa Serra do Sol isso não ocorreu e nota-se, pelo teor dos votos e do conteúdo da ementa, que a fundamental ponderação de valores - afinal o direito fundamental dos índios a uma vida digna em sentido lato não está acima do direito de propriedade dos produtores e nem do direito a uma vida digna dos não-índios ali existentes - não marcou presença no julgamento em foco como deveria.

Tributário do constitucionalismo, nossa organização política se dá pelo signo do poder limitado e respeito aos direitos fundamentais, tudo emoldurado pelo Estado de Direito como expressão da razão e de um projeto amplo de sociedade, já então inspirada pela democracia.

Essa Democracia e esse Estado de Direito, contudo, devem ser exercitados do modo mais coletivo possível e nas instâncias mais ventiladas à participação popular, o que o Poder Judiciário não tem como abrigar na amplidão devida, eis que, por natureza, deve a atividade jurisdicional primar pela abordagem técnica, desenvolvida por indivíduos com capacitação específica e adequada para a busca do lícito e do correto dentro de um sistema jurídico-normativo posto, sendo tal atividade por natureza contramajoritária.

A conservação e a promoção dos direitos fundamentais, mesmo contra o pensamento das maiorias políticas, é uma condição de funcionamento do constitucionalismo democrático. Vale ressaltar que os juízes devem agir dentro dos ditames constitucionais e das leis infraconstitucionais, deixando de lado a vontade política, e como ator social, o juiz atua em nome da sociedade devendo atuar com harmonia perante a 'vontade' social, dentro de limites plausíveis e justificáveis.

Portanto, e para tanto, a questão vital é: o ativismo judicial na intenção de proteger uma minoria, não acaba por criar outra? Com essa problemática levantada quem é a minoria a ser protegida e como ela deve ser protegida? Os produtores rurais ali envolvidos —e seus funcionários, familiares, empresas coligadas - não ficaram numa situação de ainda maior desamparo que os próprios índios?

Nada disso parece ter sido considerado no julgamento em destaque. Como já dito, o princípio a ser observado pelo STF no caso deveria ter sido o da razoabilidade. Os arrozeiros poderiam se encontrar protegidos pela Constituição, notadamente através de uma interpretação com viés econômico do art. 170, CF.

A preservação da área poderia ter preservado os conflitantes. A conservação do meio ambiente bem como a preservação indígena e dos arrozeiros, poderia ter sido feita de uma forma sustentável adequando para ambas às partes, a garantia 
da terra e do desenvolvimento social daquela região. Tal tese encontra amparo no art. 219 da Constituição Federal que aduz:

O mercado interno integra o patrimônio nacional e será incentivado de modo a viabilizar o desenvolvimento cultural e sócio-econômico, o bem-estar da população e a autonomia tecnológica do país, nos termos de lei federal.

Ocorre que ao privilegiar uma parte, os índios, criou-se um desincentivo para todo um mercado. Por ser uma parte fértil onde o cultivo de arroz se implantou de forma bem sucedida, a decisão pela preservação total da área prejudicou a produção local.

A instabilidade gerada pelas decisões do Supremo Tribunal Federal são alvos de críticas, pois ressalta a falta de legitimidade democrática da Justiça, mesmo sendo a decisão melhor que a estabelecida pelo legislador. E cria para a população uma perspectiva bastante preocupante: o eventual autoritarismo dos juízes. Uma minoria passaria a ditar os rumos de várias questões de relevo transcendental para a sociedade. Convém neste contexto lembrar o alerta de Jean-Jacques Rousseau: ${ }^{11}$

Uma das maiores ameaças à soberania popular decorre da incessante ação dos magistrados e suas vontades particulares contra a vontade geral. Para se compreender o processo de consolidação da democracia é necessário, portanto, ir além do estudo da formação da vontade democrática e analisar de que forma os órgãos encarregados de aplicar essa vontade têm cumprido a sua missão.

Um dos mais respeitados pesquisadores da atualidade, Daniel Sarmento, chama-nos a atenção para os riscos de um ativismo judicial sem limites. Elogiando a atividade jurisdicional que se propõe mais ampla, Sarmento contra-argumenta que há a "outra face da moeda" e essa é a de que muitos juízes "deslumbrados diante dos princípios e da possibilidade de através deles, buscarem a justiça —ou que entendem por justiça- passaram a negligenciar no seu dever de fundamentar racionalmente os seus julgamentos". ${ }^{12}$ E prossegue dito pesquisador:

Esta "euforia" com os princípios abriu um espaço muito maior para o decisionismo judicial. Um decisionismo travestido sob as vestes do politicamente correto, orgulhoso com seus jargões grandiloquentes e com a sua retórica inflamada, mas sempre um decisionismo. Os princípios constitucionais, neste quadro, converteram-se em verdadeiras "varinhas de condão": com eles, o julgador de plantão consegue fazer quase tudo o que quiser. Esta prática é profundamente danosa a valores extremamente caros ao Estado Democrático de Direito. Ela é prejudicial à democracia, porque permite que juízes não eleitos imponham a suas preferências e valores aos jurisdicionados, muitas vezes passando por cima de deliberações do legislador. Ela compromete a separação dos poderes, porque dilui a fronteira entre as funções judiciais e legislativas. E ela atenta contra a segurança jurídica, porque torna o direito muito menos previsível, fazendo-o dependente das idiossincrasias do juiz de

11 ROUSSEAU, Jean-Jacques. Do contrato social. São Paulo: L\&PM, 2007, p. 39.

12 SARMENTO, Daniel. Ubiquidade Constitucional: Os Dois Lados da Moeda. In NETO, Cláudio Pereira de Souza; SARMENTO, Daniel (Org.). A Constitucionalização do Direito: Fundamentos Teóricos e Aplicações Especificas. Rio de Janeiro: Lúmen Júris, p. 144. 
plantão, e prejudicando com isso a capacidade do cidadão de planejar a própria vida com antecedência, de acordo com o conhecimento prévio do ordenamento jurídico.

E outro estudioso e doutrinador, Luis Flávio Gomes, seguindo a mesma linha de Sarmento, ou seja, valorizar o ativismo, mas com uma generosa dose de cautela, igualmente observa que quando "o Poder Judiciário inova o ordenamento jurídico, criando regras antes desconhecidas, invade a tarefa do legislador, ou seja, se intromete indevidamente na função legislativa. Isso gera um outro risco: o da aristocratização do Estado e do Direito (que, certamente, ninguém no século XXI está muito disposto a aceitar)". ${ }^{13}$

O contraponto ora formulado não pode, por outro lado, servir como simples censura a uma atuação mais vigorosa dos tribunais, especialmente o STF que, inegavelmente, vem tutelando a regulamentando questões importantíssimas como o aborto de feto anencéfalo, a união homossexual, as cotas étnicas e muitas outras.

Nada obstante, o exercício do poder sempre demanda cuidado e atenção, especialmente por parte dos que o exercem. Lord Acton imortalizou a observação segundo a qual "o poder corrompe e o poder absoluto corrompe absolutamente". ${ }^{14}$

O Estado de Direito nasceu sob os auspícios de um objetivo claro: criar uma instituição que permitisse o exercício do poder político de modo limitado, afastando justamente o estado anterior de coisas, ou seja, um exercício de poder político praticamente sem limites e sujeito aos caprichos ou opiniões pessoais de seu titular.

Pode-se, estruturalmente, estar longe dos tempos de um monarca absolutista. Já, porém, a possibilidade de um exercício pontual e episódico de uma parcela desse poder estatal com alguns laivos de excesso ou abuso é algo plenamente viável, ainda que sob a égide um estado democrático de direito e com todas as garantias a ele inerentes em plena articulação e funcionamento.

\section{REFERENNCIAS}

ALBANO, Gleidson Pinheiro. Globalização da Agricultura: uma análise comparativa entre duas cidades com fruticultura irrigada para exportação no RN, Ipanguaçu e Baraúna. Disponível em https:/www.ufpe.br/posgeografia/images/documentos/d_2012_gleidson_pinheiro_albano.pdf, acesso em 19 de novembro de $201 \overline{7}$.

GOMES, Luiz Flávio. O STF está Assumindo um “Ativismo Judicial” sem Precedentes? in Revista eletrônica Universo Jurídico, disponível em www.uj.com. br, acesso em 02.11.2017.

HABERMAS, J. Direito e Democracia - entre faticidade e validade. vol. I, Rio de Janeiro: Tempo Brasileiro, 1997.

13 GOMES, Luiz Flávio. O STF está Assumindo um “Ativismo Judicial” sem Precedentes? in Revista eletrônica Universo Jurídico, disponível em www.uj.com.br, acesso em 02.11.2017.

14 Disponível em https://www.goodreads.com/author/quotes/969937.John_Emerich_Edward_Dalberg_Acton, acessado em 12 de julho de 2017. 
NALINI, José Renato. Curso de Deontologia da Magistratura. José Renato Nalini (org), São Paulo: Saraiva, 1992.

PRADO, Lídia Reis de Almeida. O juiz e a anima: reflexos sobre a prestação jurisdicional. São Paulo: EDPUC, 2003.

ROUSSEAU, Jean-Jacques. Do contrato social. São Paulo: L\&PM, 2007.

SARMENTO, Daniel. Ubiquidade Constitucional: os dois lados da moeda. In SCHMITT, Carl. O conceito do político. Petropolis: Vozes, 1992.

SILVEIRA, Alípio. A justiça inglesa hoje. in RF 160/409.

STRECK, Lenio. Novos Estudos Jurídicos. Volume 8. Nº 2. p.257-301, maio/ago. 2003. 